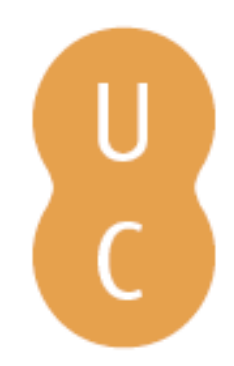

\title{
nommalina
}

\section{Áreas de risco de deslizamento de encostas no Brasil: um estudo sobre as favelas em campos do Jordão SP}

\author{
Autor(es): $\quad$ Rosa Filho, Artur \\ Publicado por: Imprensa da Universidade de Coimbra; RISCOS - Associação \\ URL \\ persistente: URI:http://hdl.handle.net/10316.2/34822 \\ DOI: $\quad$ DOI:http://dx.doi.org/10.14195/978-989-96253-3-4_31 \\ Accessed : $\quad$ 26-Apr-2023 12:21:41
}

A navegação consulta e descarregamento dos títulos inseridos nas Bibliotecas Digitais UC Digitalis, UC Pombalina e UC Impactum, pressupõem a aceitação plena e sem reservas dos Termos e Condições de Uso destas Bibliotecas Digitais, disponíveis em https://digitalis.uc.pt/pt-pt/termos.

Conforme exposto nos referidos Termos e Condições de Uso, o descarregamento de títulos de acesso restrito requer uma licença válida de autorização devendo o utilizador aceder ao(s) documento(s) a partir de um endereço de IP da instituição detentora da supramencionada licença.

Ao utilizador é apenas permitido o descarregamento para uso pessoal, pelo que o emprego do(s) título(s) descarregado(s) para outro fim, designadamente comercial, carece de autorização do respetivo autor ou editor da obra.

Na medida em que todas as obras da UC Digitalis se encontram protegidas pelo Código do Direito de Autor e Direitos Conexos e demais legislação aplicável, toda a cópia, parcial ou total, deste documento, nos casos em que é legalmente admitida, deverá conter ou fazer-se acompanhar por este aviso.

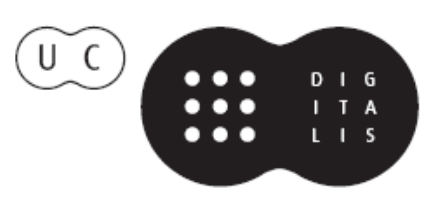



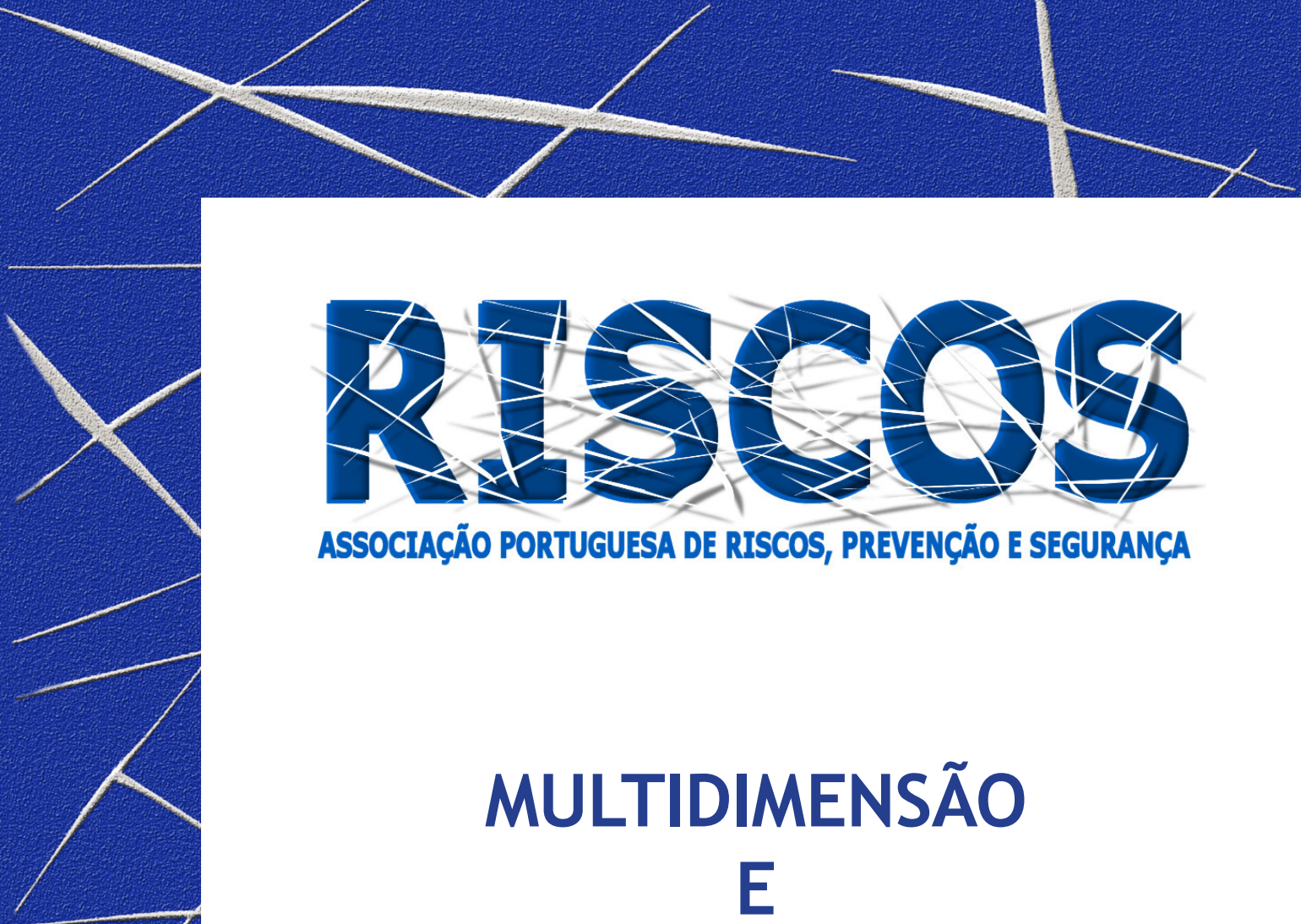

ASSOCIAÇÃO PORTUGUESA DE RISCOS, PREVENCCÃO E SEGURANÇA

MULTIDIMENSÃO

E
TERRITÓRIOS DE RISCO

III Congresso Internacional

I Simpósio Ibero-Americano

VIII Encontro Nacional de Riscos

Guimarães

2014 


\title{
ÁREAS DE RISCO DE DESLIZAMENTO DE ENCOSTAS NO BRASIL: UM ESTUDO SOBRE AS FAVELAS EM CAMPOS DO JORDÃO-SP.
}

\author{
Artur Rosa Filho \\ Departamento de Geografia da Universidade Federal de Roraima, Brasil \\ artur.filho@ufrr.br
}

\begin{abstract}
RESUMO
Nas últimas décadas do século XX e no início do século XXI , os deslizamentos de encostas têm aumentado consideravelmente, principalmente nos países subdesenvolvidos, bem como, nos países classificados como em desenvolvimento. A construção de habitações em encostas acentuadas alteram a paisagem urbana, agravando os movimentos gravitacionais de massa. Conhecida por muitos como a "Suíça brasileira", Campos do Jordão-SP, possui cerca de 47.000 habitantes. Encontramos na cidade, além de belos bairros residenciais, onde são construídos palacetes pelas elites, o seu lado triste, onde reina a miséria, a fome e o desemprego, são suas favelas, que quase nunca são vistas pelos turistas durante o Festival de Inverno. Esse estudo partiu do pressuposto de que as pessoas ao morarem em áreas de risco, ficam vulneráveis aos deslizamentos e colocam-se à mercê do acaso e nem a experiência adquirida com os deslizamentos anteriores, as livram da exposição e das tragédias que um novo deslizamento pode provocar.
\end{abstract}

Palavras chaves: favelas, áreas de risco, deslizamentos de encostas.

\section{Introdução}

O fenômeno de intensa urbanização ocorrido nas últimas décadas e o agravamento da crise econômica do Brasil reduziu as alternativas habitacionais da população de mais baixa renda. Essa população passou a ocupar áreas geologicamente desfavoráveis, sem planejamento e infra-estrutura. Esse quadro tem contribuído para o incremento das situações de risco associadas a processos do meio físico. Grande parte dessas situações está associada aos escorregamentos e processos correlatos. Esses têm provocado acidentes com graves danos sociais e econômicos em várias cidades, além de danos diversos em obras civis (estradas, dutovias etc.) em diferentes regiões.

Segundo Cerri (1993), no Estado de São Paulo, encontramos zonas de média, alta e muito alta suscetibilidade a movimentos gravitacionais de massa, tanto, como fenômenos da dinâmica natural de evolução do relevo, quanto processos induzidos pela ocupação. Destacam-se, pela grande freqüência de acidentes associados a deslizamentos, a região da Serra do Mar (Baixada Santista e Litoral Norte), a Região Metropolitana de São Paulo e o Vale do Paraíba, assim como a Serra da Mantiqueira (Campos do Jordão).

Esses deslizamentos constituem riscos da natureza, que provocam conseqüências graves como, por exemplo, o bloqueio de vias de circulação, o soterramento de casas e, conseqüentemente, a ocorrência de vítimas fatais. Além disso, provocam diversos danos ambientais, alterando a paisagem urbana e, com isso, tornando a mesma mais vulnerável a novas ocorrências.

$\mathrm{O}$ objetivo geral da pesquisa foi realizar um estudo, através de uma abordagem perceptiva, dos deslizamentos de encostas nas favelas em áreas de risco no município de Campos do Jordão-SP. O conjunto desses estudos, sob o ponto de vista da sociedade urbana de Campos do Jordão, nos permitiu a elaboração de uma crítica mais consistente sobre as precárias condições de moradia e o baixo padrão de vida dos moradores residentes na favela Britador, como pode ser observado na fotografia um (1), localizada em encostas acentuadas, sujeitas à riscos de deslizamentos. 


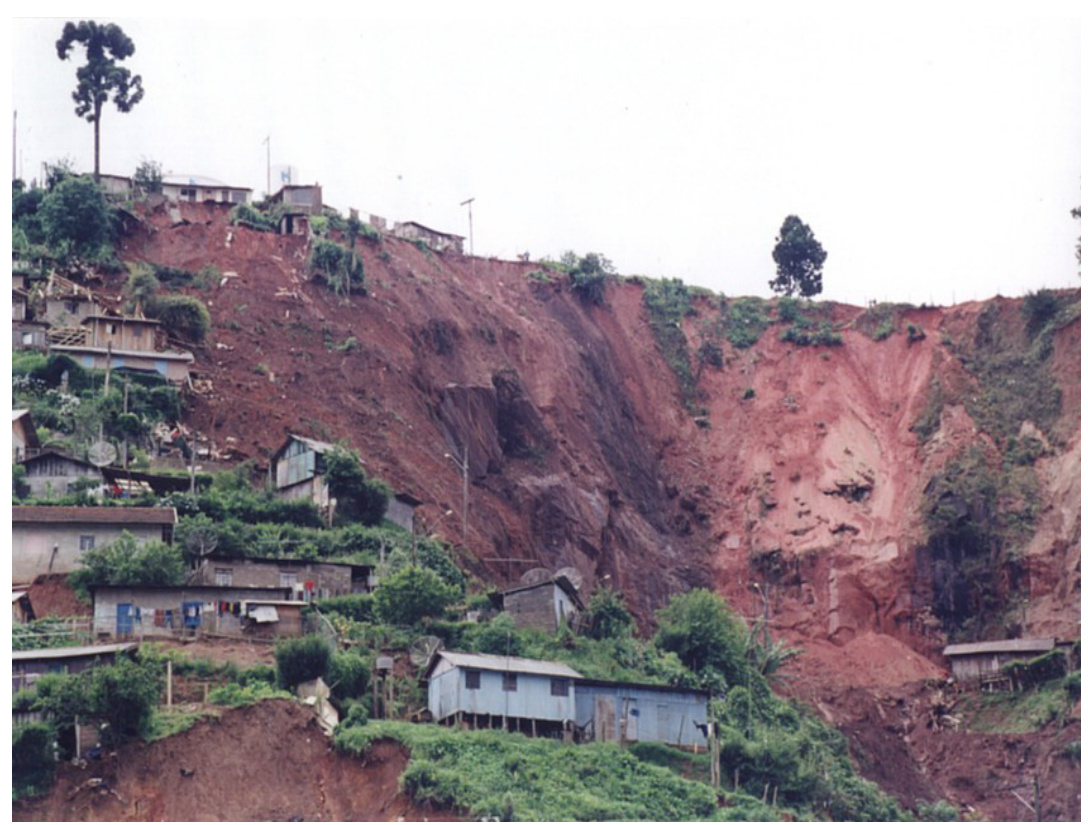

Fotografia.1- Favela Britador-Campos do Jordão-SP Fonte: Sidnei Silva, 2000

A pesquisa fundamentou-se na procura de respostas humanas para a problemática da ocupação urbana em áreas de riscos de deslizamentos. A abordagem perceptiva dada na pesquisa pode contribuir para a tomada de consciência dos sujeitos que moram nessas áreas de risco.

Esse estudo partiu do pressuposto de que as pessoas, que sem opções na escolha do local de moradia, ficam vulneráveis aos deslizamentos de encostas e colocam-se à mercê do acaso. Não sabendo quando irá acontecer um deslizamento, ficam despreparadas para a ocorrência do fato.

Além disso, essas pessoas possuem pouca informação e poucos recursos quando se deparam com um deslizamento. Nem a experiência adquirida com os deslizamentos anteriores as livram da exposição e das tragédias que um novo deslizamento pode provocar.

Entretanto, embora vivendo em áreas de risco, os moradores das favelas Britador e Santo Antônio permanecem no local, sendo possível identificar em suas percepções: a) não têm para onde ir; b) não têm condições de pagar aluguel; c) já vivem nas encostas há muito tempo, possuindo raízes históricas com o local; d) pensam sempre que o risco pode ocorrer com o outro e nunca consigo mesmo.

Os moradores das favelas não ignoram o risco, mas permanecem no local, sobretudo pela imposição do quadro econômico com o qual lidam, e, também, devido a laços afetivos que mantêm com o lugar.

\section{“A Suiça Brasileira" e as Favelas}

Conhecida por muitos como a "Suíça brasileira", Campos do Jordão, com cerca de 45.000 habitantes, apresenta, além de belos bairros residenciais, onde são construídos palacetes pelas 
elites, o seu lado pobre e triste, onde reina a miséria, a fome e o desemprego. Suas favelas abrigam muitas pessoas, entre crianças e adultos, que necessitam, principalmente na época do frio, da nossa compreensão e ajuda material.

Para Oliveira (1991), aproximadamente $56 \%$ da população encontram-se na condição de favelados. Para ele, antigamente, o povoamento das favelas em Campos do Jordão estava associado aos migrantes em busca de trabalho, mas a partir dos anos 80 , o crescimento passou a estar relacionado mais diretamente com as demandas requeridas pela economia.

As favelas em Campos do Jordão surgiram na década de 1940 como mostra a fotografia dois (2). Mas, foi a partir dos anos 70 do século XX, que tiveram início as grandes invasões nas áreas verdes, áreas de lazer dos loteamentos e áreas particulares, todas nos morros da cidade.

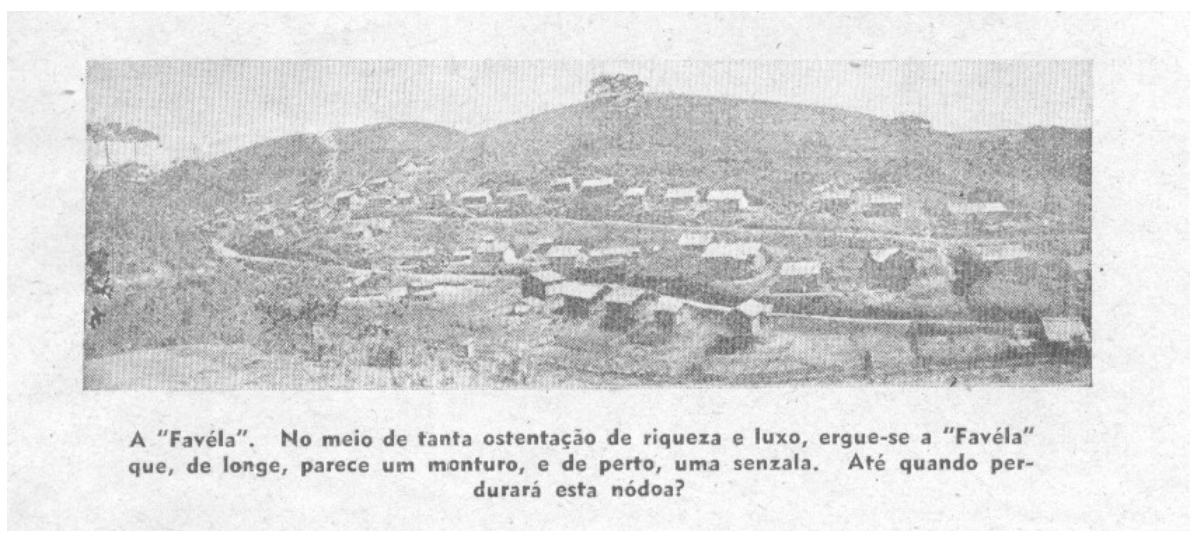

Fotografia. 2 Surgimento das favelas em Campos do Jordão Fonte: Condelac C. Andrade, 1948

Muitos imóveis nas "Vilas Operárias" de Vila Albertina, Morro das Andorinhas, Britador, Vila Santo Antonio, Vila Maria e outros locais foram ocupados com o incentivo de autoridades que deveriam ter coibido essas ações. Sérios e fatais deslizamentos ocorreram e dezenas de vidas foram perdidas no bairro da Vila Albertina nos anos de 1972 e 2002.

\section{Conclusão}

Ao analisar a questão inicial, por que essa população não deixa as áreas de risco, mesmo sabendo do perigo, levantou-se a priori, que a principal dificuldade em sair da área está na decorrência da falta de outras perspectivas de lugar de moradia. Entendemos que essas favelas configuram-se, sob a lógica da urbanização brasileira, como áreas de segregação sócio-espacial, representativas das periferias das cidades turísticas e/ou industriais.

Observou-se que essas pessoas apresentam uma certa acomodação em relação ao seu local de moradia, chegando a quase um estado de inércia, o que dificulta a remoção dos mesmos para outras áreas. Há ainda a percepção do perigo distorcido, ou seja, o morador percebe que o perigo pode acontecer com o outro e nunca consigo mesmo. 
Alem disso, há fatores de ordem econômica, cultural e histórica que corroboram para esse estado de inércia desses moradores. Estas questões foram investigadas a partir de pesquisas técnicas, pesquisas de campo, entrevistas com moradores e turistas, aplicação de questionário. A pesquisa bibliográfica foi importante para ampliar a leitura sobre o tema e, sobretudo, ultrapassar a imagem criada pela mídia de que Campos do Jordão, a "Suíça Brasileira", limitase a apenas ser uma cidade turística de inverno. É esta mesma imagem que ao atrair novos moradores, em busca de uma vida melhor, acaba por impor-lhes uma precária condição de vida urbana, quase sempre sem perspectivas de mudança.

As condições precárias de submoradias e o baixo padrão de vida dos moradores dessas favelas decorrem, quase sempre, do baixo padrão de remuneração que obtêm em subempregos, da localização das favelas, localização esta em relação à acessibilidade social, ou seja, aos "benefícios" urbanos e, ainda, das políticas públicas que reiteram a segregação sócio-espacial no município.

\section{Bibliografia}

CERRI, Leandro Eugenio Silva. 1993. Riscos Geológicos Associados a Escorregamentos: Uma Proposta para a Prevenção de Acidentes. Tese de Doutorado. UNESP. Rio Claro-SP.

OLIVEIRA, José Oswaldo Soares de. 1991. A Quem Interessa a Urbanização Clandestina? Estudos sbre Campos do Jordão. Dissertação de Mestrado. Escola de Engenharia de São Carlos- USP-SP.

ROSA FILHO, Artur. 2006. Percepção Geográfica de Escorregamentos de Encostas em Favelas nas Áreas de Risco-Campos do Jordão-SP. Tese de Doutorado. Universidade Estadual Paulista-UNESP-Rio ClaroSP. 